\title{
Small-Size Seven-Band WWAN/LTE Antenna with Distributed LC Resonant Circuit for Smartphone Application
}

\author{
Yan-Wu Liang and Hao-Miao Zhou \\ College of Information Engineering, China Jiliang University, Hangzhou 310018, China \\ Correspondence should be addressed to Hao-Miao Zhou; zhouhm@cjlu.edu.cn
}

Received 4 February 2015; Accepted 6 May 2015

Academic Editor: Ahmed T. Mobashsher

Copyright (C) 2015 Y.-W. Liang and H.-M. Zhou. This is an open access article distributed under the Creative Commons Attribution License, which permits unrestricted use, distribution, and reproduction in any medium, provided the original work is properly cited.

A compact small-size coupled-fed antenna composed of an inverted L-shaped feeding strip and a shorting strip with double branches for the WWAN/LTE bands operation in the internal smartphone application is presented. With the help of a novel distributed LC resonant circuit, the proposed antenna can not only realize the miniaturization $\left(15 \times 28 \times 4 \mathrm{~mm}^{3}\right)$ and multiband to cover 2G/3G/4G bands but also be tuned and optimized easily. The measured bandwidth with $3: 1 \mathrm{VSWR}$ is $163 \mathrm{MHz}$ (804$967 \mathrm{MHz})$ at the low-band and $1615 \mathrm{MHz}(1665-3280 \mathrm{MHz})$ at the high-band. What is more, the lowest measured efficiency in the whole frequency band is more than $52 \%$ for practical applications. The operating principles and main parameters are detailed below. And successful simulation, fabrication, and measurement of the proposed antenna are shown in this paper.

\section{Introduction}

With the rapid development of mobile communication networks, mobile phone terminal should not only cover the operation bands of the second generation GSM850/ 900/1800/1900 and the third generation UMTS2100 mobile communication systems but also meet the requirement of the mobile systems operation bands of the fourth generation LTE2300/2500. The space for antenna is becoming smaller and smaller with the increasing size of the mobile phone. Due to the decrease of mobile phone antenna size and increase of the operation bands, miniaturization and multiband of mobile phone terminal antenna become hot and difficult in the antenna design. At the same time, the aim of easy manufacture, high efficiency, and saving the production cost makes the design of a novel mobile phone antenna more challenging.

At present, there are already a lot of researches about multiband mobile phone [1-16] and tablet computer [17, 18] antennas, including GSM850 (824-894 MHz), GSM900 (890-960 MHz), GSM1800 (1710-1880 MHz), GSM1900 (1850-1990 MHz), UMTS2100 (1920-2170 MHz), LTE2300
(2305-2400 MHz), and LTE2500 (2500-2690 MHz). When the internal antenna occupies too much space, it will affect the installation of other GPS or Bluetooth antennas, induce a strong coupling of the multiple antennas, and reduce the communication quality [2]. In order to better achieve the miniaturization and multiband, many technologies have been studied, such as coupling feed technology [3-7, 17], slot loaded technology $[8,17]$, reconfigurable technology $[9,10]$, a parallel resonant loaded technology [11], double planar inverted-E (PIE) feed structure [12], loading the matching network $[13,14,18]$, loading lumped elements technology [18], and loading printed distributed inductance technology $[15,16]$. Table 1 lists the dimensions and performance of WWAN/LTE antenna for the same frequency bands and applications in recent works. Loading a printed distributed inductance [15] can not only shift the resonant point to the lower frequency and achieve the purpose of miniaturization but also improve the radiation efficiency relative to load lumped elements and be conveniently processed and manufactured. However, the antenna in that paper only operates in WWAN bands. Later, by using the loading printed distributed inductance technology, Ban et al. successfully 
TABLE 1: Comparison of proposed antenna with reference antennas.

\begin{tabular}{|c|c|c|c|c|}
\hline Antenna & Frequency bands covered & Antenna size $\left(\mathrm{mm}^{2}\right)$ & $\begin{array}{c}\text { Bandwidth }(\mathrm{MHz}) \\
\text { (Low/High) }\end{array}$ & $\begin{array}{c}\text { Efficiency (\%) } \\
\text { (Low/High) }\end{array}$ \\
\hline Proposed antenna & $\begin{array}{c}\text { GSM850/900/GSM1800/1900/ } \\
\text { UMTS2100/LTE2300/2500 }\end{array}$ & $28 \times 15$ & $163 / 1615$ & $52-65 / 54-74$ \\
\hline Reference [6] & Same as above & $45 \times 15$ & $227 / 1310$ & $39-73 / 43-70$ \\
\hline Reference [16] & Same as above & $29 \times 15$ & $210 / 1210$ & $41-55 / 43-80$ \\
\hline Reference [19] & Same as above & $60 \times 8$ & $205 / 1040$ & $40-55 / 44-70$ \\
\hline Reference [20] & Same as above & $55 \times 12$ & $169 / 1030$ & $24-44 / 40-78$ \\
\hline
\end{tabular}

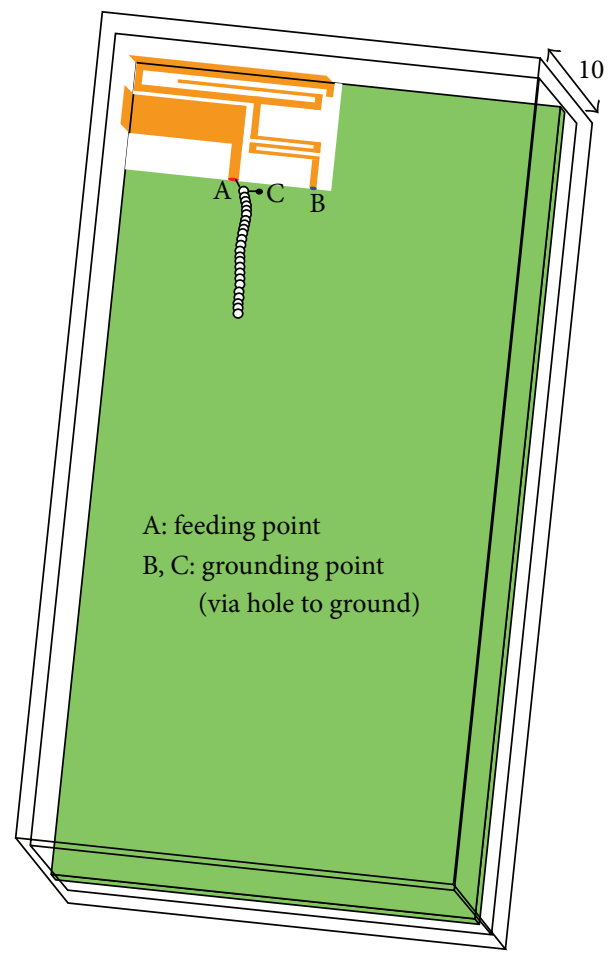

(a)

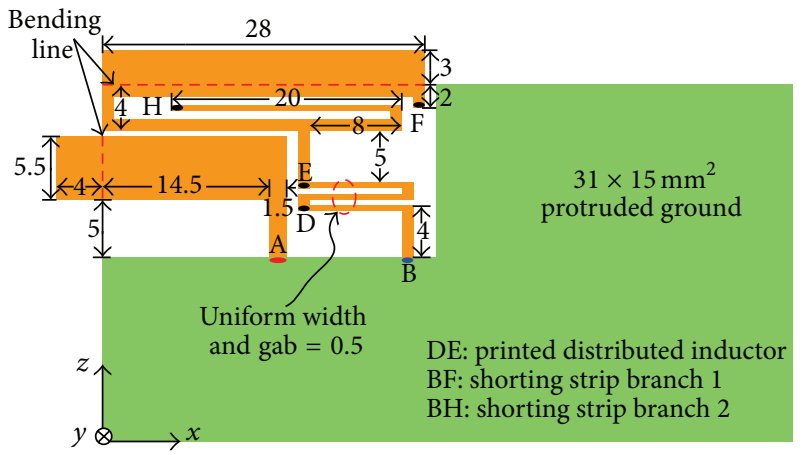

(b)

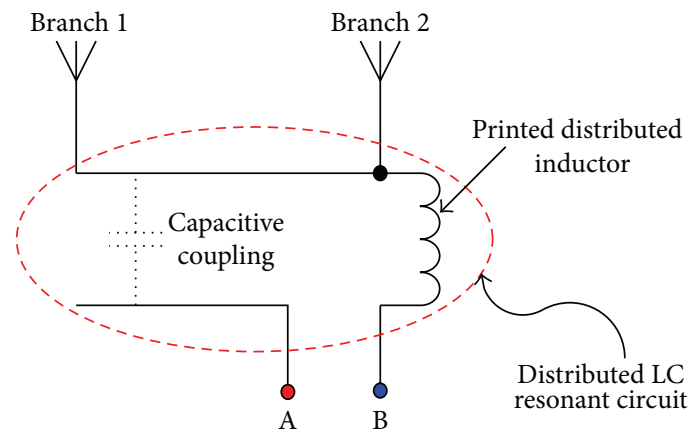

(c)

FIGURE 1: Proposed antenna configuration: (a) geometry of the proposed seven-band antenna with distributed LC resonant circuit. (b) Dimensions of the metal pattern in the antenna area (unit: $\mathrm{mm}$ ). (c) Equivalent circuit diagram of the proposed antenna. 
designed a printed antenna with excellent performance for the WWAN/LTE bands operation to improve the antenna structure [16]. A capacitive coupled loop antenna with dual branches [7] reaches the aim of multiband, but the volume is $11 \times 46 \times 7 \mathrm{~mm}^{3}$, which can not achieve the miniaturization. As we all know, the loading lumped elements technology can reduce the size of the antenna, but it increases the ohmic loss [18] and reduces the radiation efficiency of the antenna. Thus the mobile phone antenna whose area is less than $15 \times$ $30 \mathrm{~mm}^{2}$ for seven WWAN/LTE bands operation without lumped elements loading is rare.

Inspired by the above antenna $[7,15,16,18]$ and to achieve the miniaturization and multiband, improve radiation efficiency, simplify processing, and save the cost, a novel smallsize seven-band WWAN/LTE antenna with a distributed LC resonant circuit for smartphone application is proposed in this paper. The proposed antenna is composed of an inverted L-shaped feeding strip and a shorting strip with double branches. A distributed LC resonant circuit is formed by a printed distributed inductor and the capacitive coupling between inverted L-shaped feeding strip and shorting strip branch 1, which can cover low-band (GSM850/900) and high-band (LTE2300/2500). The shorting strip branch 2 can cover sub-high-band (GSM1800/1900/UMTS2100) by the coupled-fed excitation. The proposed antenna is easily printed on the circuit board without loading any lumped element and only occupies a small volume of $15 \times 28 \times 4 \mathrm{~mm}^{3}$, which makes it suitable for smartphone application. In this paper,using a printed distributed inductance instead of a chip inductance not only is convenient for antenna manufacturing but also reduces the antenna loss and indirectly increases the radiation efficiency of the proposed antenna.

\section{Proposed Antenna Configuration}

Figure 1(a) shows the geometry of the proposed smallsize seven-band WWAN/LTE antenna with distributed LC resonant circuit for smartphone application. In this study, the proposed antenna is easily printed on a $0.8 \mathrm{~mm}$ thick FR4 substrate of size $60 \times 115 \mathrm{~mm}^{2}$, relative permittivity 4.4 , and loss tangent 0.02 . The proposed antenna is mounted on the bottom edge of the system circuit board and only occupies a small volume of $15 \times 28 \times 4 \mathrm{~mm}^{3}$, so that it saves space for other components of the smartphone and reduces the specific absorption rate (SAR) on the human body. The system ground planes are printed on the back of the FR4 substrate, including a main ground plane of $60 \times 100 \mathrm{~mm}^{2}$ and a protruded ground plane of $15 \times 31 \mathrm{~mm}^{2}$. To reduce the influence of the protruded ground plane and achieve a compact antenna structure, as shown in Figure 1(b), the distance between the proposed antenna and the protruded ground plane is $1 \mathrm{~mm}$. In order to simulate actual phone boxes and be close to experiment results, $1 \mathrm{~mm}$ thick plastic housing (height $10 \mathrm{~mm}$, relative permittivity 3.3, and conductivity $0.02 \mathrm{~S} / \mathrm{m}$ ) is used to enclose the proposed antenna in this study. What is more, one end-portion (point A) of the feeding strip is the feeding point of the proposed antenna, which is excited by $50 \Omega$ coaxial feed line. The end-portion (point B)

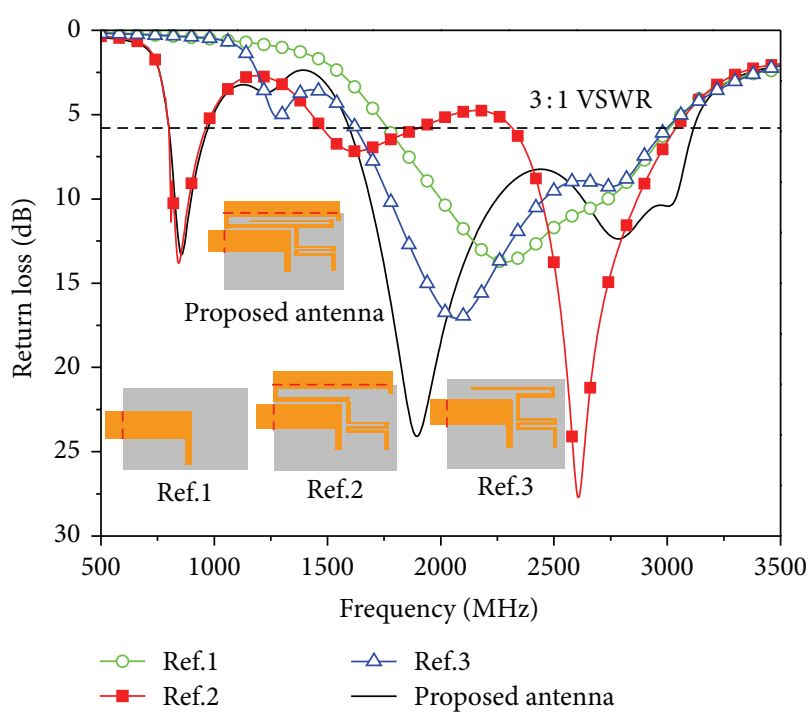

Figure 2: Comparison between the simulated return loss of the proposed antenna and three antennas for reference with the feeding strip only (Ref.1), with the feeding strip and the shorting strip branch 1 (Ref.2), and with the feeding strip and the shorting strip branch 2 (Ref.3).

of the coupling strip is directly connected to the main ground plane through a via-hole in the system circuit board.

Detailed size parameters of the antenna have been given in Figure 1(b), including two parts: an inverted L-shaped feeding strip and a shorting strip with double branches (shorting strip branch 1 and shorting strip branch 2). Firstly, the feeding strip is resonant at $2.25 \mathrm{GHz}$ with a length of about $25 \mathrm{~mm}$, which generates a wide operating band to cover 1.7$3 \mathrm{GHz}$ (only feeding strip). Secondly, Figure 1(c) shows an equivalent circuit diagram of the proposed antenna, a distributed LC resonant circuit formed by a printed distributed inductor and the capacitive coupling between inverted Lshaped feeding strip and shorting strip branch 1 (about $90 \mathrm{~mm}$ ) can cover the low-band and the high-band. Finally, the shorting strip branch 2 (about $70 \mathrm{~mm}$ ) contributes to the sub-high-band with the coupled-fed excitation. The heights of two upright antenna radiation plates of the feeding strip and the shorting strip 1 are $4 \mathrm{~mm}$ and $3 \mathrm{~mm}$, respectively, which is promising for modern slim smartphone application, and this upright structure saves the internal space of mobile phones effectively.

\section{Design Process and Parameter Analysis}

In order to analyze the design process of the proposed antenna, Figure 2 shows the comparison between the simulated return loss of the proposed antenna and three antennas for reference (Ref.1: only the feeding strip; Ref.2: the feeding strip and the shorting strip branch 1; Ref.3: the feeding strip and the shorting strip branch 2). For Ref.1, it only generates a resonance at about $2.25 \mathrm{GHz}$. To cover the low-band, as shown in Figure 2, Ref.2 suggests 


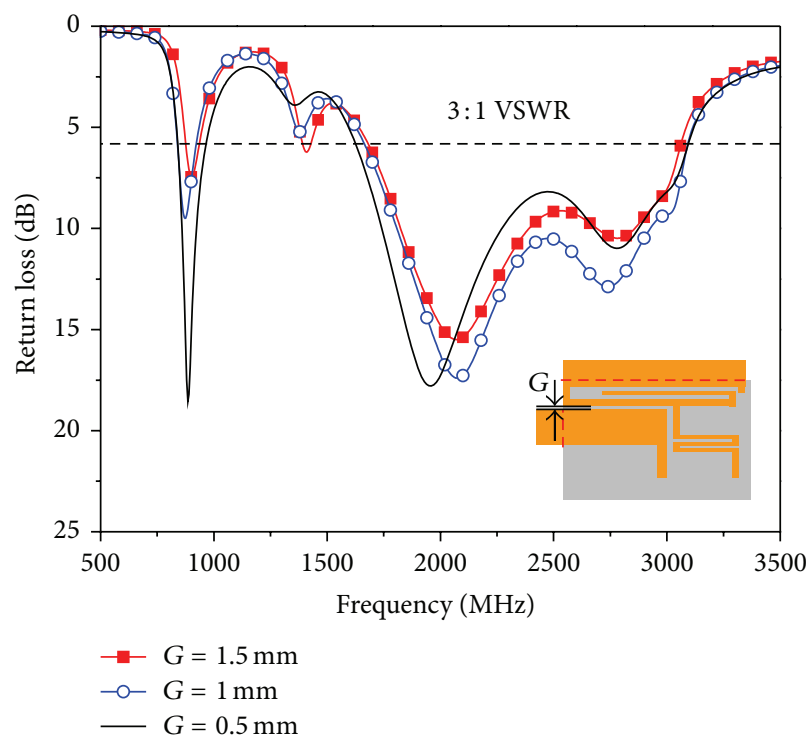

(a)

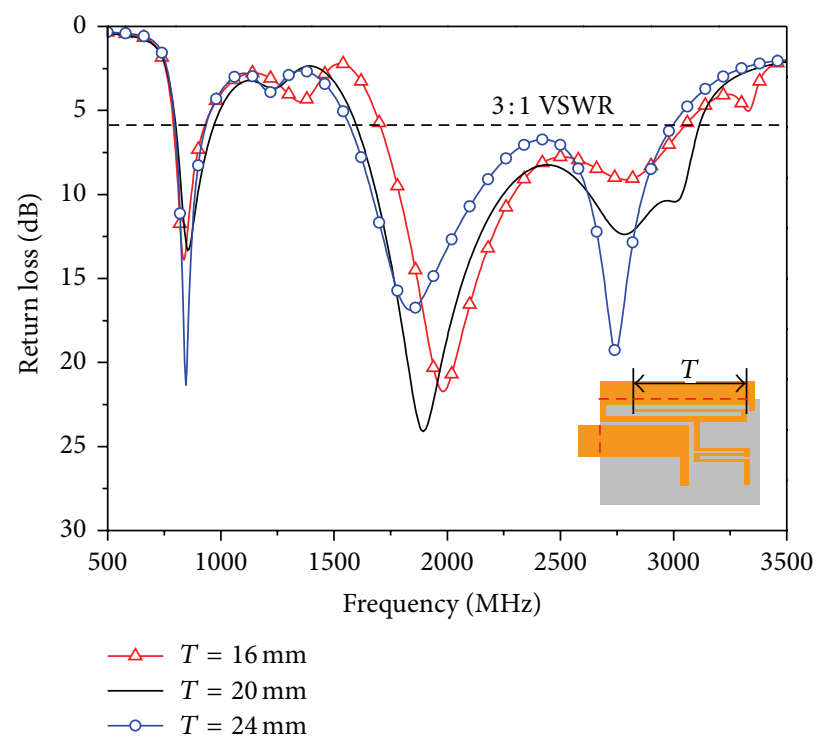

(b)

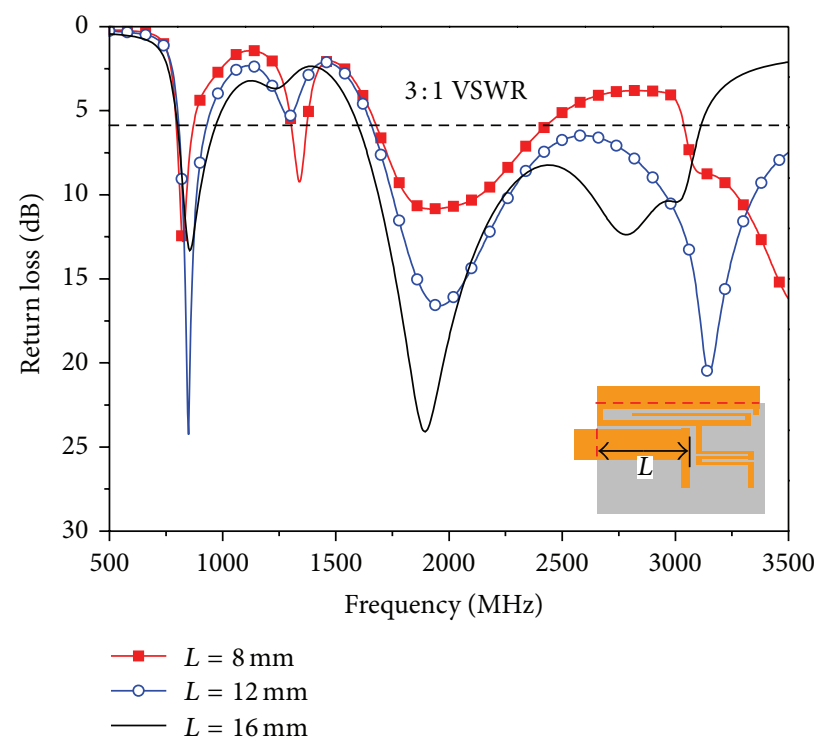

(c)

FIGURE 3: Simulated return loss as a function of (a) the coupling gap width G between the feeding strip and the shorting strip branch 1, (b) the length $T$ of the end of the shorting strip branch 2, and (c) the length $L$ of the feeding strip.

that a distributed LC resonant circuit can cover low-band and high-band and shift the high resonant mode from $2.25 \mathrm{GHz}$ to $2.6 \mathrm{GHz}$, but not completely cover the bands (GSM1800/1900/UMTS2100/LTE2300/2500). So Ref.3 proposes another coupled-fed structure formed by the inverted L-shaped feeding strip and the shorting strip branch 2, which realizes the coverage of sub-high-band. Finally, by the accumulation of the shorting strip branch 1 and the shorting strip branch 2 , the proposed antenna can operate in all WWAN/LTE bands successfully.

To understand the structure of the proposed antenna better, the main parameters have been studied. First, the paper mentions a distributed LC resonant circuit based on a distributed inductance DE section, whose purpose is to control the capacitive coupling between the inverted L-shaped feeding strip and the shorting strip branch 1. Figure 3(a) shows the simulated return loss results of different coupling gap width $G$ varying from $0.5 \mathrm{~mm}$ to $1.5 \mathrm{~mm}$. When the coupling gap width $G$ is $0.5 \mathrm{~mm}$, the proposed antenna can achieve a good capacitive coupling to completely cover the low-band. Next, the effects of the length $T$ are analyzed in Figure 3(b); as the length $T$ is increasing from $16 \mathrm{~mm}$ to $24 \mathrm{~mm}$, the first high-frequency resonance point shifts from $2 \mathrm{GHz}$ to $1.8 \mathrm{GHz}$ correspondingly. Finally, as can be seen 

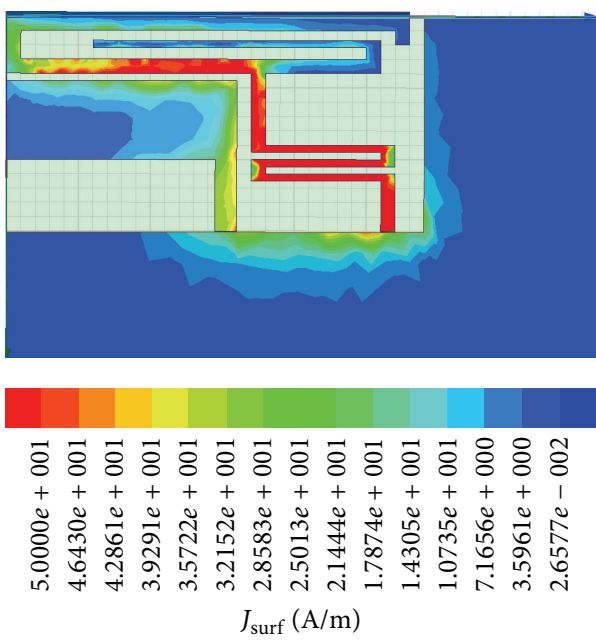

(a)
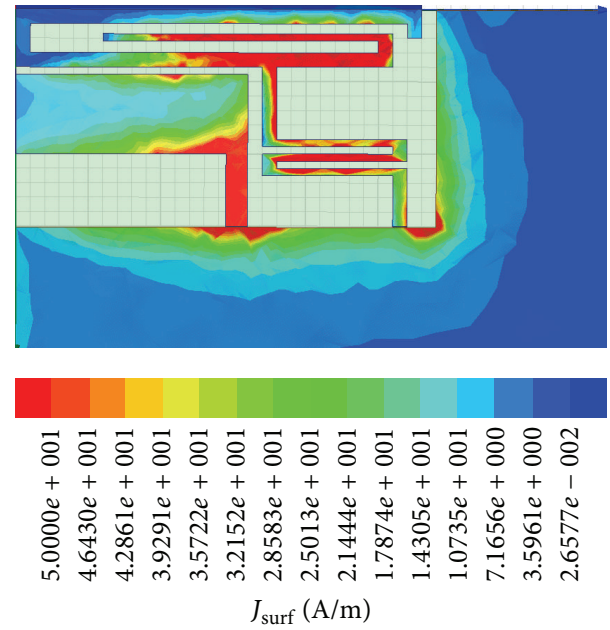

(b)
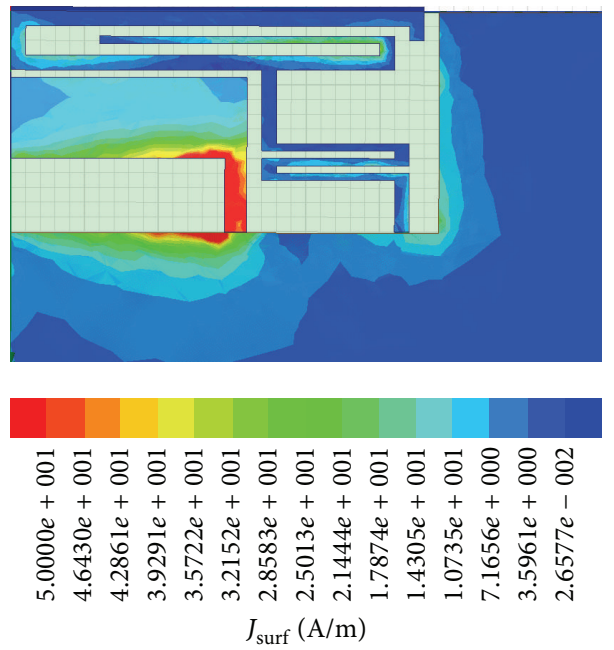

(c)

FIGURE 4: Simulated surface current distributions on the printed metal strip for the proposed antenna at (a) $860 \mathrm{MHz}$, (b) $1.9 \mathrm{GHz}$, and (c) $2.65 \mathrm{GHz}$.

from Figure 3(c), with the length $L$ increasing from $8 \mathrm{~mm}$ to $16 \mathrm{~mm}$, the second high-frequency resonance point shifts from $3.5 \mathrm{GHz}$ to $2.6 \mathrm{GHz}$ gradually; the low-band is widened simultaneously, so that high and low bands can achieve a good impedance matching.

Figure 4 shows the simulated surface current distributions on the printed metal strip for the proposed antenna at $860 \mathrm{MHz}, 1.9 \mathrm{GHz}$, and $2.65 \mathrm{GHz}$. Figure $4(\mathrm{a})$ gives the surface current distribution of $860 \mathrm{MHz}$; it is obviously observed that strong currents are on the feeding strip and the shorting strip branch 1, which indicates that the resonant mode at $860 \mathrm{MHz}$ is contributed mainly by the distributed LC resonant circuit. Similarly, Figure 4(b) shows that the resonant mode at $1.9 \mathrm{GHz}$ is generated mainly by the coupled-fed structure between the feeding strip and the shorting strip branch 2, while Figure 4(c) shows that the resonant mode at $2.65 \mathrm{GHz}$ is generated mainly by the feeding strip. Of course, the printed antenna is a unitary radiation system composed of the feeding strip, a shorting strip with double branches, and the mobile phone ground plane, which covers the $824-960 \mathrm{MHz}$ and $1710-2690 \mathrm{MHz}$ bands.

For better explanation of the role of the distributed inductance DE section, Figure 5 compares the simulated return loss of the proposed antenna and another two antennas for reference (Ref.4: simple shorting strip and Ref.5: a chip inductor instead of the distributed inductance DE section). When a simple shorting strip is used in Ref.4, whose resonant mode is about $900 \mathrm{MHz}$, it can not completely cover GSM850/900 bands. Through a bent strip DE section which plays a role in the distributed inductance, the resonant mode shifts from $900 \mathrm{MHz}$ to $860 \mathrm{MHz}$ successfully, so the proposed antenna achieves better impedance matching and completely covers the low-band. When a $2 \mathrm{nH}$ chip inductor replaces the distributed inductance DE section (Ref.5), the simulated return loss of Ref.5 and the proposed antenna is 


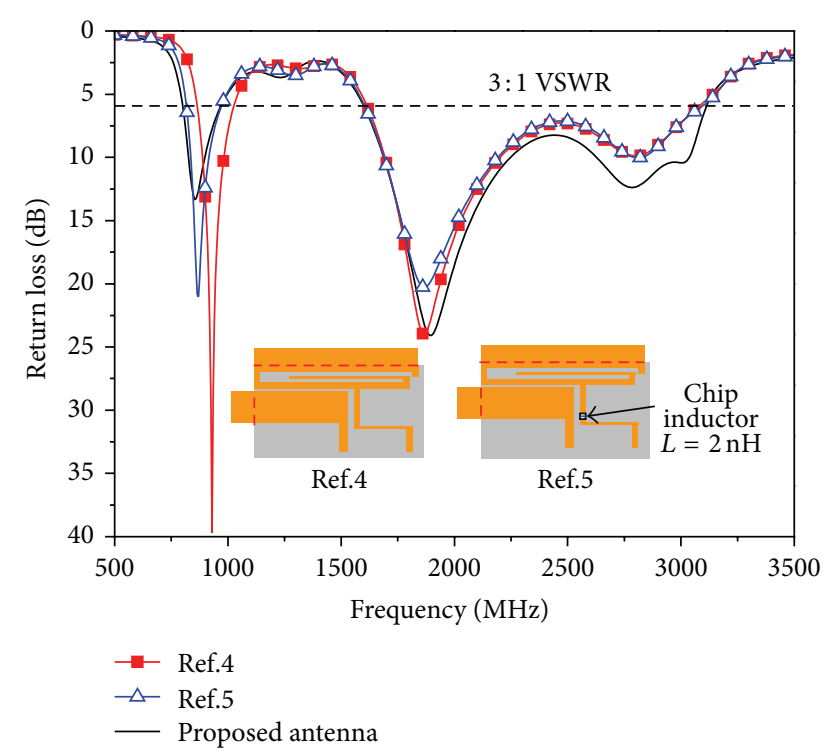

FIGURE 5: Comparison of simulated return loss for the proposed antenna, reference antenna with simple shorting strip (Ref.4), and reference antenna with a chip inductor instead of the distributed inductance DE section (Ref.5).

almost completely coincident, which proves that the bent strip DE section is equivalent to an inductive shorting strip. Furthermore, from the comparison of the proposed antenna and Ref.4, the bandwidth at high-band and two high-frequency resonance points do not change, while the low-frequency resonance point shifts to lower frequency, so that the resonant mode of low-band can be easily tuned and optimized for the purpose of getting the desired band, such as LTE700 (698-787 MHz).

\section{Experimental Results and Discussion}

The proposed antenna has been successfully fabricated and measured. Figure 6 shows the front and back photos of the fabricated antenna. Results of the measured and simulated return loss are shown in Figure 7. The simulated results are obtained by using electromagnetic simulation software, and measured results are tested by a vector network analyzer (Agilent N5230C). The bandwidth with $3: 1$ VSWR of low-band is $163 \mathrm{MHz}(804-967 \mathrm{MHz})$, while the bandwidth of high-band is $1615 \mathrm{MHz}(1665-3280 \mathrm{MHz})$, which fully cover the sevenband WWAN/LTE antenna. Good agreement between the measured and the simulated results in the operation bands can be seen in Figure 7. The little deviation is mainly due to the presence of fabrication (size errors of antenna processing) and measurement (effect of coaxial cable welding) error.

The radiation patterns of the fabricated antenna are measured in SATIMO anechoic chamber. Figure 8 shows the measured radiation patterns at 900,1900 , and $2670 \mathrm{MHz}$. For $900 \mathrm{MHz}$ in Figure 8(a), the radiation patterns of the proposed antenna are similar to a dipole antenna in the $x-y$ plane, which have a good omnidirectional performance, indicating

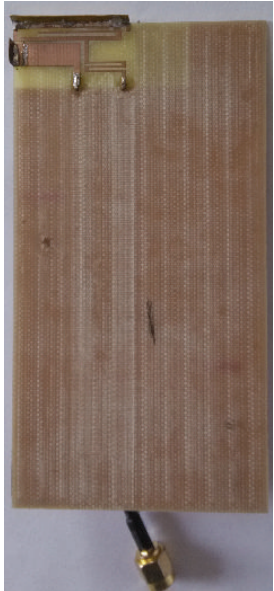

(a)

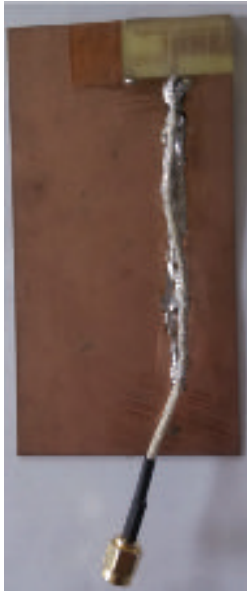

(b)
FIgURE 6: Photos of the fabricated antenna: (a) front side and (b) back side.

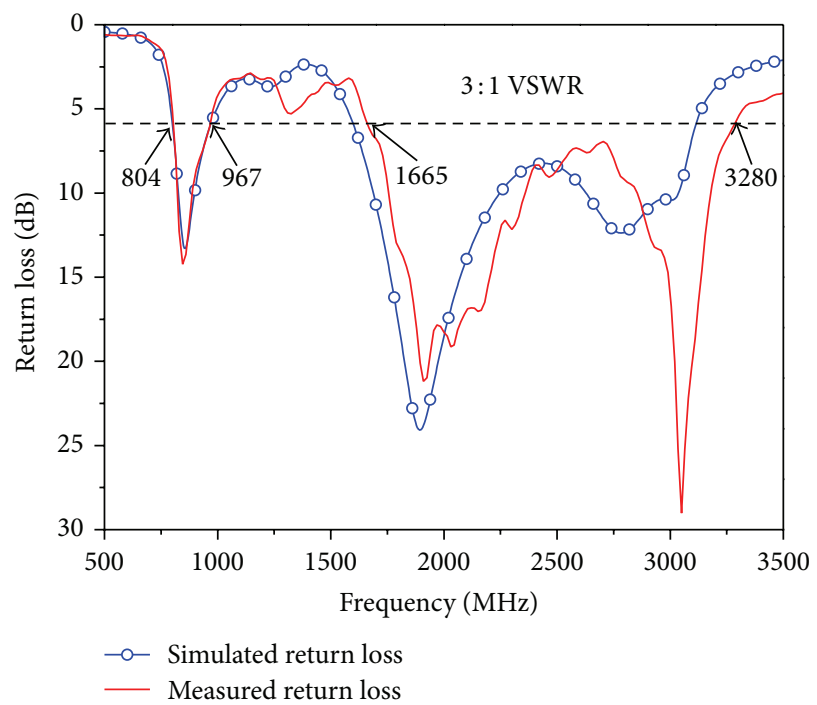

FIGURE 7: Measured and simulated return loss for the fabricated antenna.

that radiation characteristic of the proposed antenna at the low-band is relatively stable. While at 1900 and $2670 \mathrm{MHz}$, the radiation patterns have some changes, mainly due to the high-order resonance. In fact, the ground plane of mobile phone system is an effective radiator in the low-band and a reflector in high-band, which has a greater influence on radiation characteristic of mobile antenna.

Figure 9 shows the measured antenna gain and radiation efficiency. Over the desired $824-960 \mathrm{MHz}$ band, the antenna gain varies from about -0.5 to $1 \mathrm{dBi}$ and the radiation efficiency ranges from about $52 \%$ to $65 \%$. Over the desired $1710-2690 \mathrm{MHz}$ band, the fabricated antenna gain varies from about 1 to $3.9 \mathrm{dBi}$, and the radiation efficiency ranges from about $54 \%$ to $74 \%$. The measured radiation characteristics 

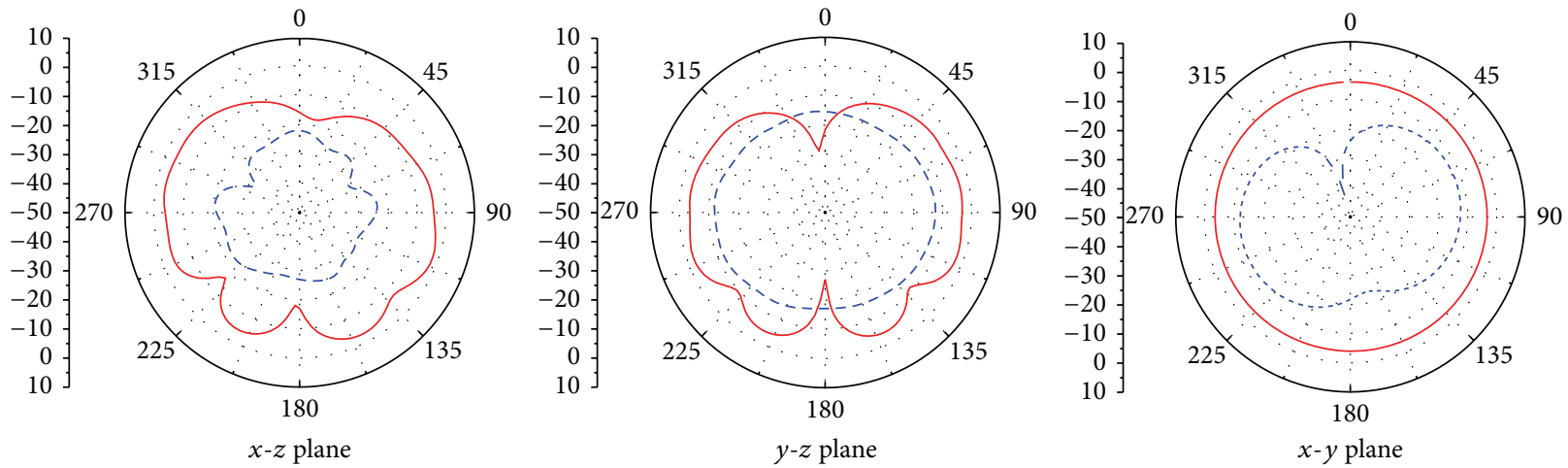

(a) $900 \mathrm{MHz}$
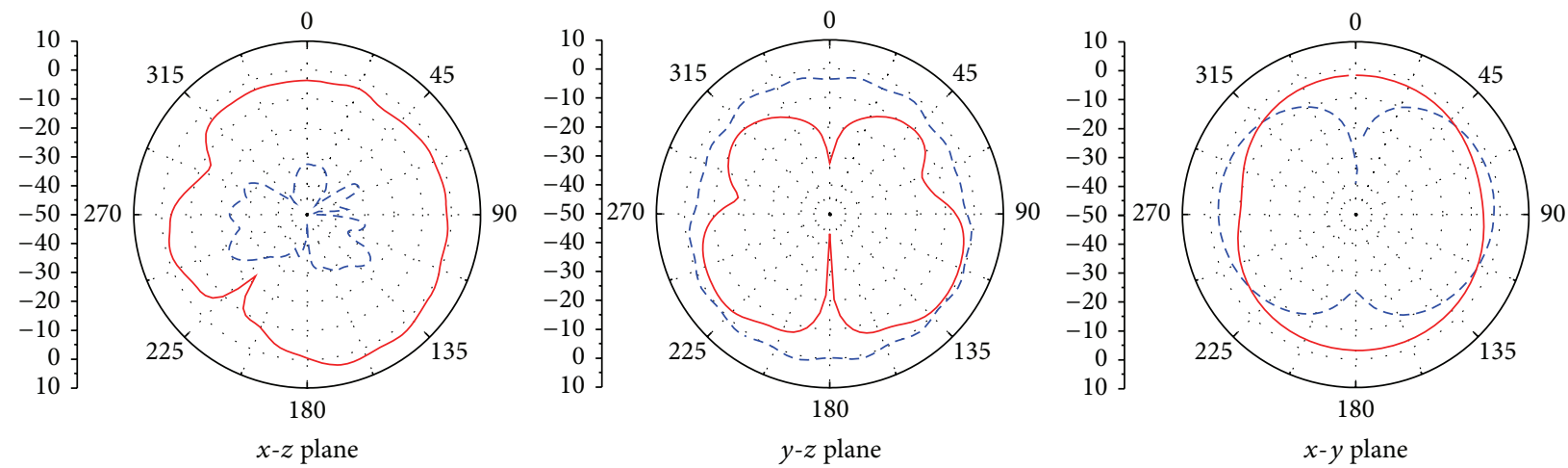

(b) $1900 \mathrm{MHz}$
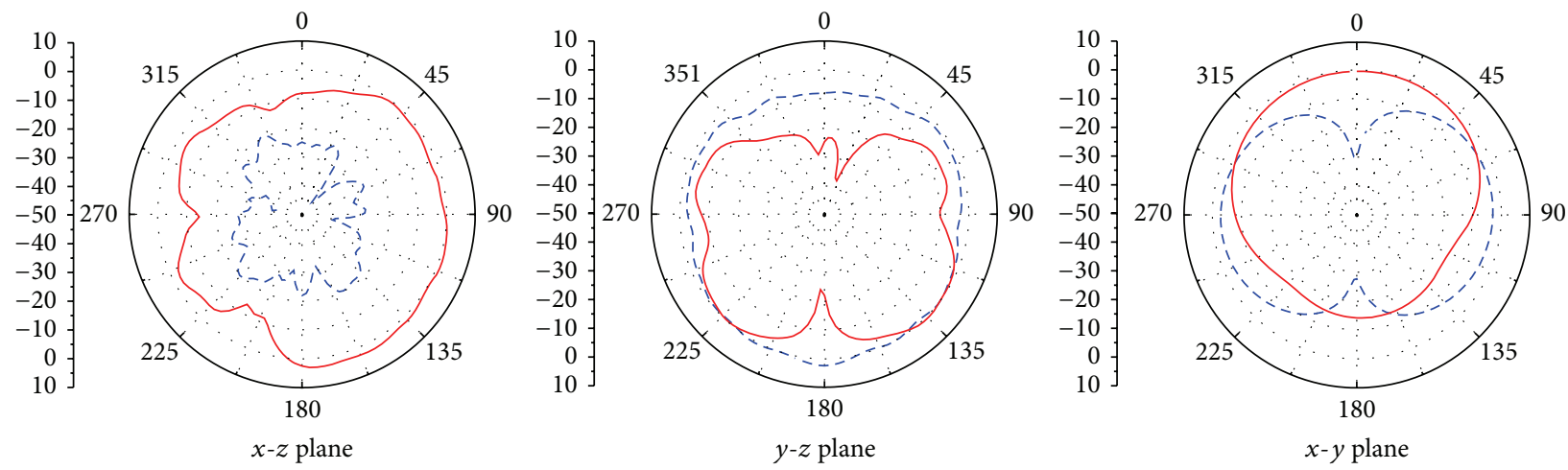

(c) $2670 \mathrm{MHz}$

Figure 8: Measured 2-D radiation patterns at (a) $900 \mathrm{MHz}$, (b) $1900 \mathrm{MHz}$, and (c) $2670 \mathrm{MHz}$ for the fabricated antenna (dotted line is $E_{\varphi}$, and solid line is $E_{\theta}$ ).

suggest that the proposed antenna is acceptable for practical mobile communication application.

Finally, the influence of the electronic components on the antenna performance is also discussed. The electronic components, including Universal Serial Bus (USB) and microphone, are installed on the surface of the protruded ground plane. Figure 10 shows the measured return loss for the proposed antenna and Ref.6 (the case with a USB and a microphone). It can be seen that there are very little effects of electronic components on the antenna performance. Therefore, the proposed antenna can be integrated with a variety of electronic components in a close distance for the actual mobile phone application.

\section{Conclusion}

This paper presents a novel small-size internal WWAN/LTE mobile phone antenna. With the help of a printed distributed inductor, it gets two wide operating bands of $804-967 \mathrm{MHz}$ and $1665-3280 \mathrm{MHz}$, and the antenna only occupies a small size of $15 \times 28 \times 4 \mathrm{~mm}^{3}$, which realizes the demand of miniaturization and multiband. The main parameters of 


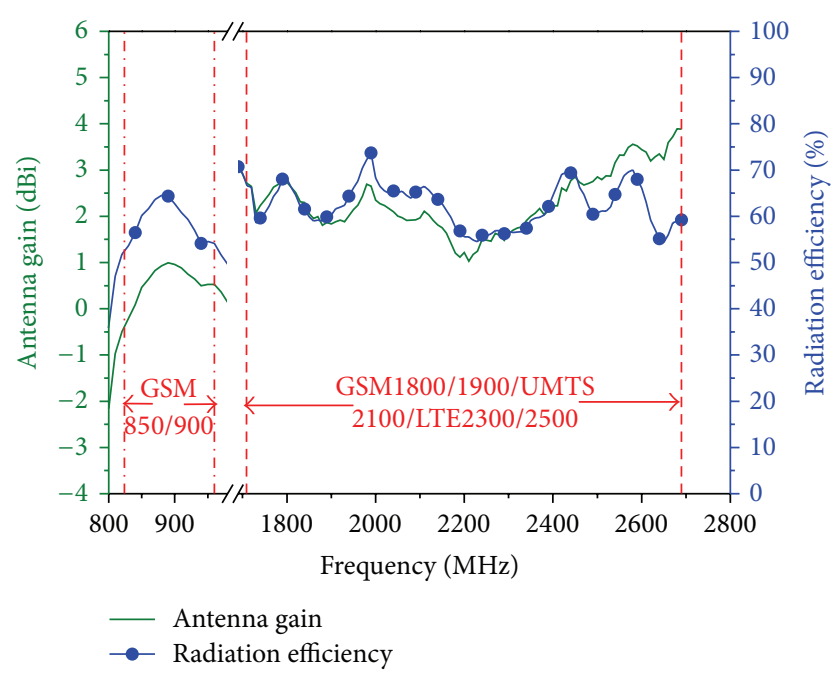

FIGURE 9: Measured antenna gain and radiation efficiency for the fabricated antenna.

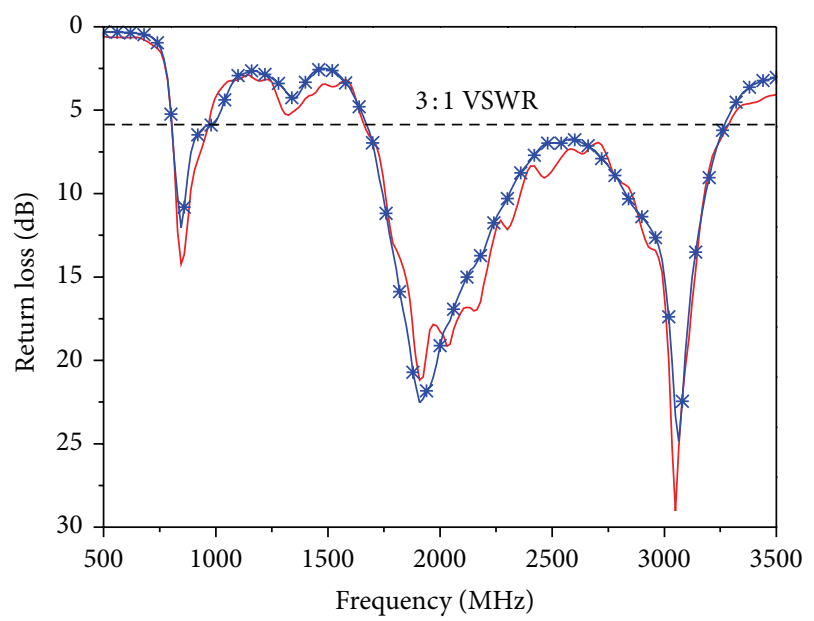

Measure

— Without USB and microphone (proposed)
* With USB and microphone (Ref.6)

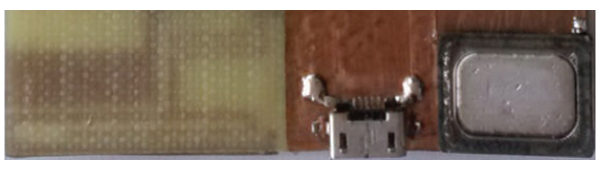

Ref.6

Figure 10: Comparison of measured return loss for the proposed antenna and the case with a USB and a microphone (Ref.6).

the proposed antenna are studied and discussed in this paper, and the performance parameters of fabricated antenna are tested, including the return loss, radiation pattern, and radiation efficiency and gain. The proposed antenna achieves a good impedance matching and the radiation efficiency is greater than $52 \%$ in the whole of the desired operating bands. Therefore, the proposed small-size WWAN/LTE antenna is quite competitive for the practical application.

\section{Conflict of Interests}

The authors declare that there is no conflict of interests regarding the publication of this paper.

\section{Acknowledgments}

This research was supported by the Fund of the National Natural Science Foundation of China under Grants nos. 11172285 and 11472259 and Zhejiang Provincial Natural Science Foundation of China under Grant no. LR13A020002. The authors would like to express their sincere appreciation to this support.

\section{References}

[1] K. L. Wong, Planar Antennas for Wireless Communications, Wiley, New York, NY, USA, 2003.

[2] Y. W. Chi and K. L. Wong, "Quarter-wavelength printed loop antenna with an internal printed matching circuit for GSM/DCS/PCS/UMTS operation in the mobile phone," IEEE Transactions on Antennas and Propagation, vol. 57, no. 9, pp. 2541-2547, 2009.

[3] T. Zhang, R.-L. Li, G.-P. Jin, G. Wei, and M. M. Tentzeris, "A novel multiband planar antenna for GSM/UMTS/LTE/ Zigbee/ RFID mobile devices," IEEE Transactions on Antennas and Propagation, vol. 59, no. 11, pp. 4209-4214, 2011.

[4] D.-G. Kang and Y. Sung, "Coupled-fed planar printed shorted monopole antenna for LTE/WWAN mobile handset applications," IET Microwaves, Antennas and Propagation, vol. 6, no. 9, pp. 1007-1016, 2012.

[5] Z. L. Xie, W. B. Lin, and G. L. Yang, "Coupled-fed printed antenna for LTE mobile handset applications," Microwave and Optical Technology Letters, vol. 56, no. 8, pp. 1752-1756, 2014.

[6] J.-H. Chen, Y.-L. Ban, H.-M. Yuan, and Y.-J. Wu, "Printed coupled-fed PIFA for seven-band GSM/UMTS/LTE WWAN mobile phone," Journal of Electromagnetic Waves and Applications, vol. 26, no. 2-3, pp. 390-401, 2012.

[7] C.-W. Yang, Y.-B. Jung, and C. W. Jung, "Octaband internal antenna for 4G mobile handset," IEEE Antennas and Wireless Propagation Letters, vol. 10, pp. 817-819, 2011.

[8] Z. Chen, Y.-L. Ban, J.-H. Chen, J. L.-W. Li, and Y.-J. Wu, "Bandwidth enhancement of LTE/WWAN printed mobile phone antenna using slotted ground structure," Progress in Electromagnetics Research, vol. 129, pp. 469-483, 2012.

[9] Y. Li, Z. J. Zhang, J. F. Zheng, Z. H. Feng, and M. F. Iskander, "A compact hepta-band loop-inverted F reconfigurable antenna for mobile phone," IEEE Transactions on Antennas and Propagation, vol. 60, no. 1, pp. 389-392, 2012.

[10] S. Lee and Y. Sung, "Reconfigurable PIFA with a parasitic strip line for a hepta-band WWAN/LTE mobile handset," IET Microwaves, Antennas \& Propagation, vol. 9, no. 2, pp. 108-117, 2015.

[11] Y.-L. Ban, J.-H. Chen, S. Yang, J. L.-W. Li, and Y.-J. Wu, "Lowprofile printed octa-band LTE/WWAN mobile phone antenna using embedded parallel resonant structure," IEEE Transactions on Antennas and Propagation, vol. 61, no. 7, pp. 3889-3894, 2013.

[12] S. Jeon, S. Oh, H. H. Kim, and H. Kim, "Mobile handset antenna with double planar inverted-E (PIE) feed structure," Electronics Letters, vol. 48, no. 11, pp. 612-614, 2012. 
[13] Y.-L. Ban, Y.-F. Qiang, Z. Chen, K. Kang, and J. L.-W. Li, "Lowprofile narrow-frame antenna for seven-band WWAN/LTE smartphone applications," IEEE Antennas and Wireless Propagation Letters, vol. 13, pp. 463-466, 2014.

[14] C. S. Yang, P. C. Huang, and C. F. Jou, "A penta-band planar inverted-F antenna for mobile phone application using LCtank-stacked network," Progress In Electromagnetics Research Letters, vol. 50, pp. 41-47, 2014.

[15] C. H. Chang and K. L. Wong, "Small-size printed monopole with a printed distributed inductor for pentaband WWAN mobile phone application," Microwave and Optical Technology Letters, vol. 51, no. 12, pp. 2903-2908, 2009.

[16] Y.-L. Ban, C.-L. Liu, J. L.-W. Li, J. Guo, and Y. Kang, "Small-size coupled-fed antenna with two printed distributed inductors for seven-band WWAN/LTE mobile handset," IEEE Transactions on Antennas and Propagation, vol. 61, no. 11, pp. 5780-5784, 2013.

[17] J. H. Lu and Z. W. Lin, "Planar compact LTE/WWAN monopole antenna for tablet computer application," IEEE Antennas and Wireless Propagation Letters, vol. 12, pp. 147-150, 2013.

[18] L. Y. Chen and K. L. Wong, "Combined-type dual-wideband antenna for 2G/3G/4G tablet device," Microwave and Optical Technology Letters, vol. 56, no. 12, pp. 2799-2805, 2014.

[19] C. J. Deng, Y. Li, Z. J. Zhang, and Z. H. Feng, "A novel low-profile hepta-band handset antenna using modes controlling method," IEEE Transactions on Antennas and Propagation, vol. 63, no. 2, pp. 799-804, 2015.

[20] Y. Hong, J. Tak, J. Baek, B. Myeong, and J. Choi, "Design of a multiband antenna for LTE/GSM/UMTS band operation," International Journal of Antennas and Propagation, vol. 2014, Article ID 548160, 9 pages, 2014. 

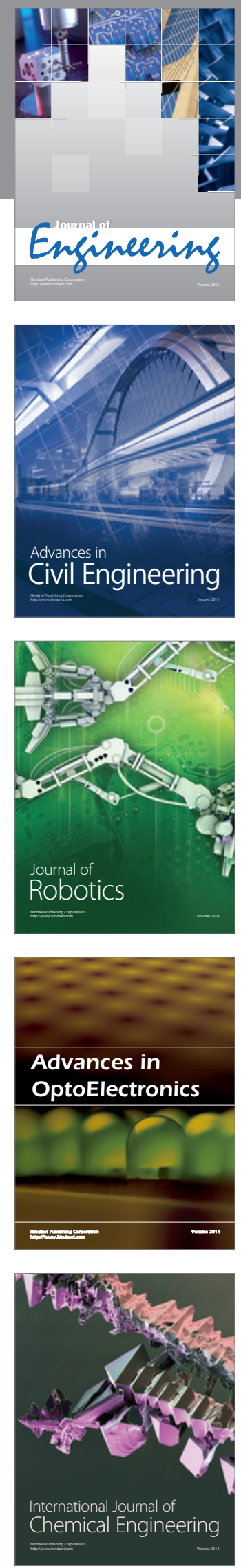

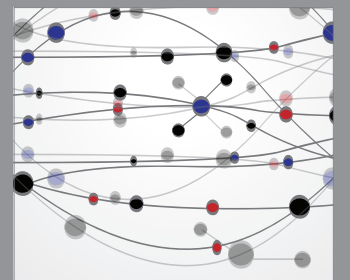

The Scientific World Journal
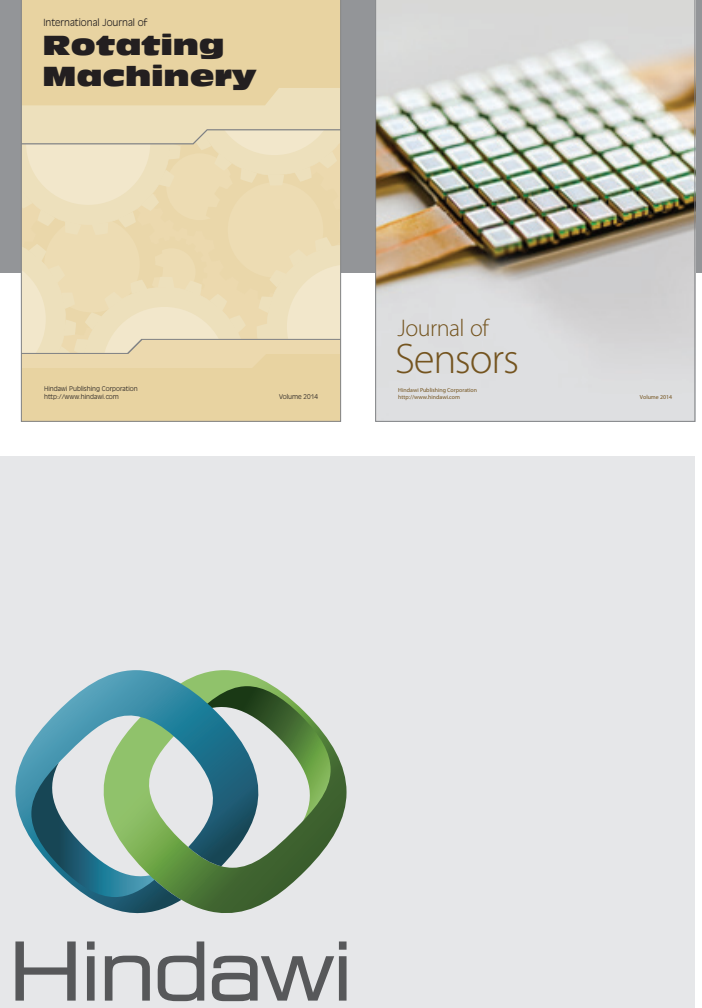

Submit your manuscripts at http://www.hindawi.com
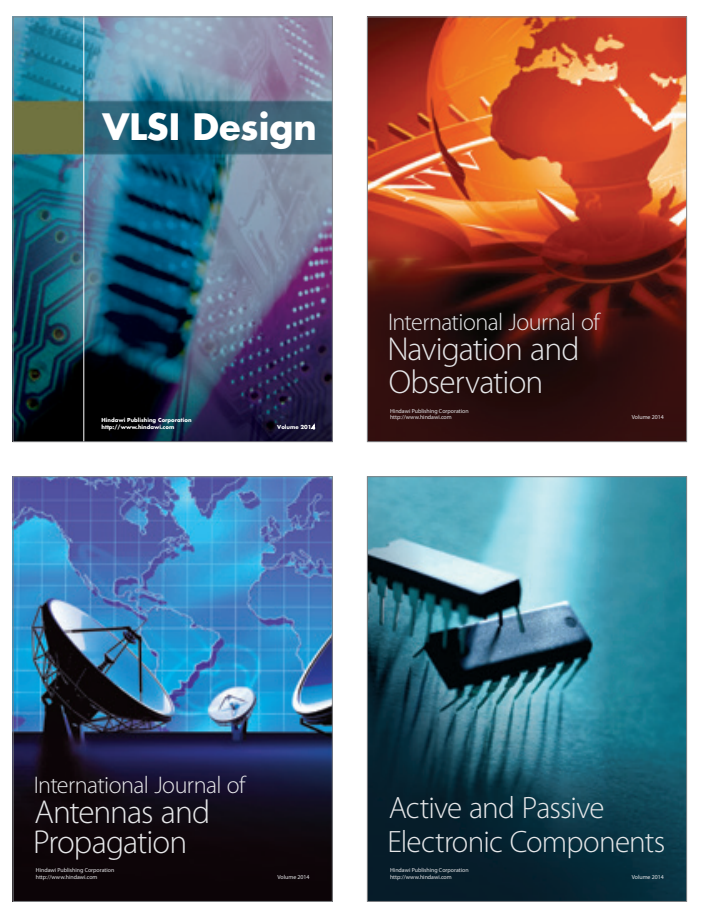
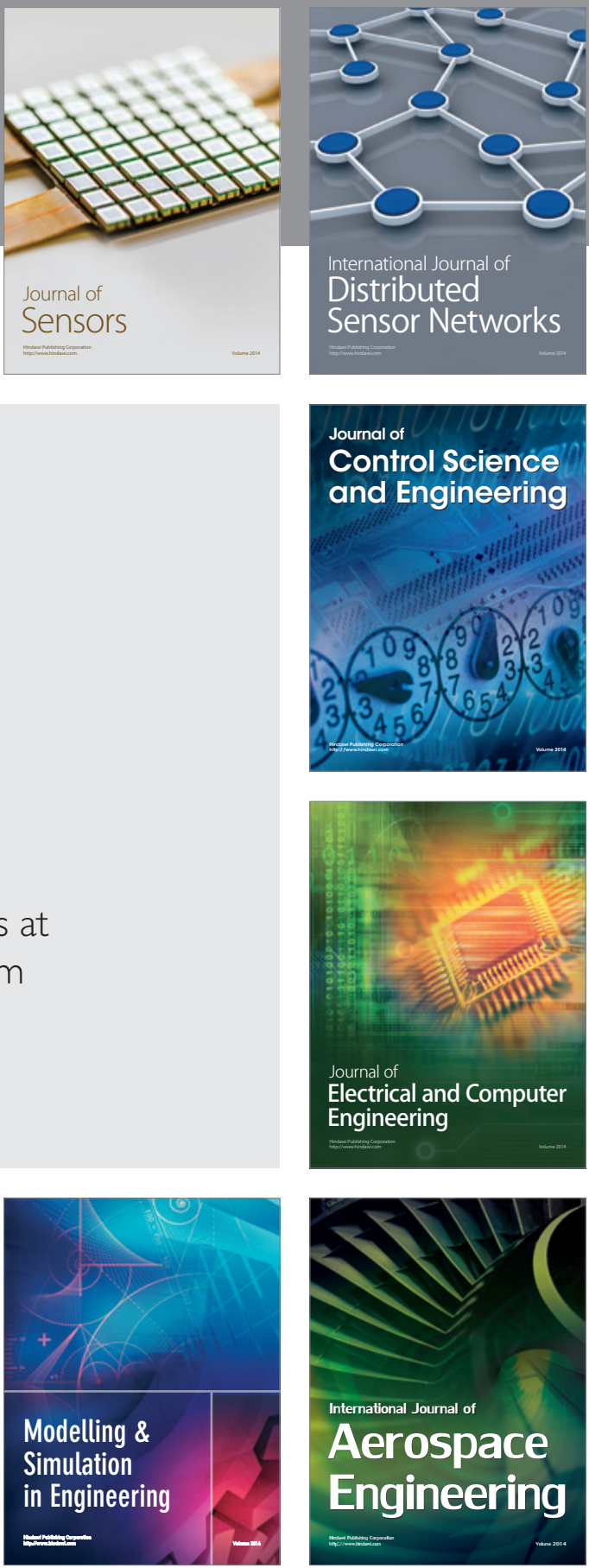

Journal of

Control Science

and Engineering
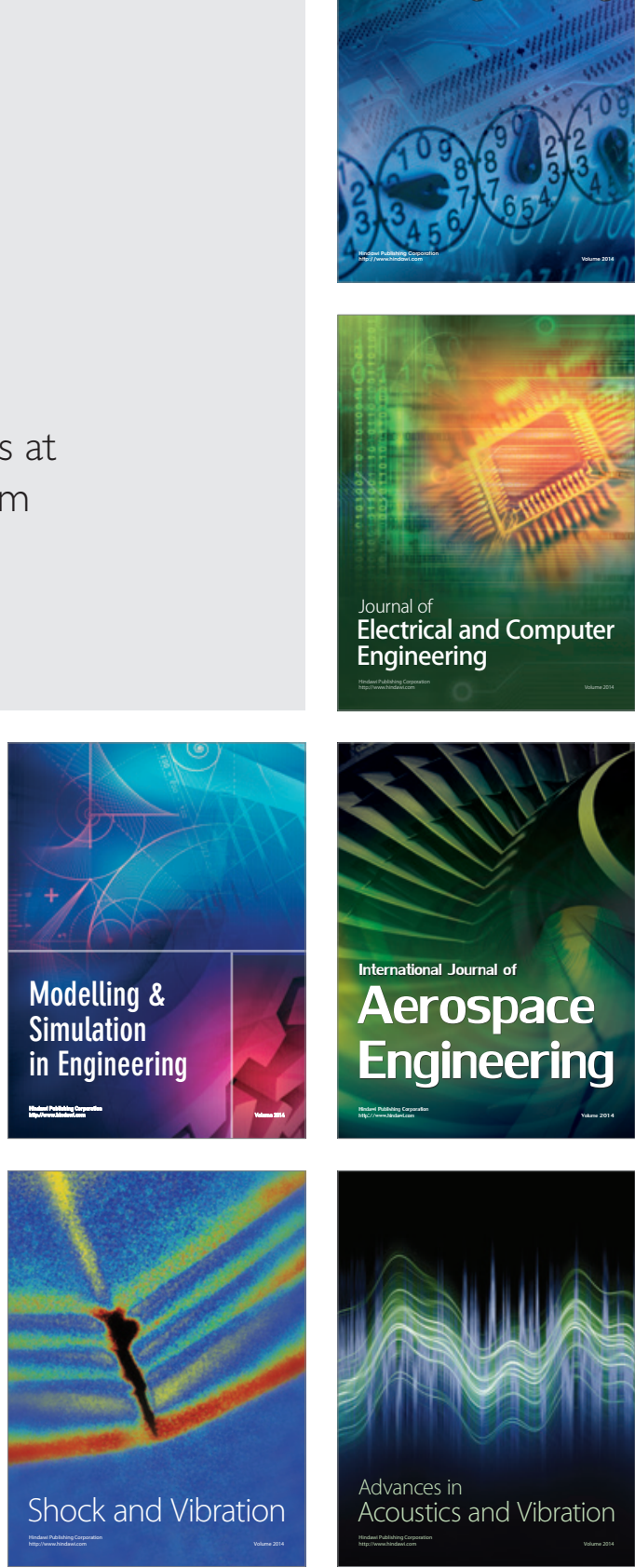